\title{
La pluriactivité dans le port de Dieppe : Hôtes- vendeurs et guerre de course à la fin du Moyen Âge
}

Pluriactivity in the port of Dieppe. Hôtes-vendeurs and privateering at the end of the Middle Ages

Philippe Lardin

\section{(2) OpenEdition}

Journals

Édition électronique

URL : http://journals.openedition.org/abpo/2615

DOI : $10.4000 / a b p o .2615$

ISBN : $978-2-7535-2843-7$

ISSN : 2108-6443

Éditeur

Presses universitaires de Rennes

Édition imprimée

Date de publication : 30 juin 2013

Pagination : 17-38

ISBN : 978-2-7535-2838-3

ISSN : 0399-0826

Référence électronique

Philippe Lardin, «La pluriactivité dans le port de Dieppe : Hôtes-vendeurs et guerre de course à la fin du Moyen Âge", Annales de Bretagne et des Pays de l'Ouest [En ligne], 120-2 | 2013, mis en ligne le 30 juin 2015, consulté le 20 avril 2019. URL : http://journals.openedition.org/abpo/2615 ; DOI : 10.4000/ abpo. 2615 


\title{
La pluriactivité dans le port de Dieppe : hôtes-vendeurs et guerre de course à la fin du Moyen Âge
}

\author{
Philippe LARDIN \\ EA 3831 GRHIS - Université de Rouen
}

Dans les ports normands, la pêche était une activité fondamentale qui apportait une relative aisance aux habitants et des revenus importants aux seigneurs. À Dieppe, les taxes qui pesaient sur la pêche fournissaient ainsi à l'archevêque de Rouen, seigneur de la ville, une part considérable de ses revenus. Pourtant, cette activité reposait essentiellement sur la prise des harengs qui ne durait que cinq à six semaines par an et constituait ce qu'on appelait la " harengaison ". Pendant le reste de l'année, l'activité des pêcheurs et de ceux qui écoulaient leur production se réduisait considérablement même si d'autres espèces de poisson pouvaient encore être pêchées beaucoup plus loin au large. Ceux qui vivaient de la pêche aux harengs devaient donc trouver d'autres activités, à l'instar de ceux qui écoulaient les produits de la pêche et qui s'adonnaient à d'autres activités commerciales ou politiques.

Les pêcheurs, eux, ne pouvaient guère que continuer à aller en mer, en changeant de proie, c'est-à-dire en pratiquant " la guerre de course " qui les amenait à attaquer les bateaux marchands ou pêcheurs qui passaient au large de Dieppe et à ramener leurs prises dans le port où ils devaient payer des droits d'entrée à l'archevêque qui prenait donc, lui aussi, sa part sur cette activité guerrière généralement illégale. Les comptabilités de la seigneurie archiépiscopale, les registres de tabellionage qui nous sont parvenus, même s'ils sont incomplets, nous permettent de décrire partiellement cette pluriactivité pratiquée par les principaux acteurs de la vie économique et sociale du port.

\section{Le système des hôtes}

Lorsqu'ils rentraient au port, les pêcheurs devaient payer à l'archevêché des droits d'entrée appelés " coutumes " qui représentaient 
l'essentiel des recettes de la seigneurie. Un bateau qui apportait moins de 4450 harengs devait laisser le dixième de la valeur de sa pêche ${ }^{1}$. S'il en rapportait davantage, il devait la valeur d'un millier de harengs à la meilleure vente, c'est-à-dire au meilleur prix à la date du déchargement. Cette législation locale ne s'appliquait pas à tous les pêcheurs puisque de nombreuses exemptions avaient été accordées aux occupants de ce qu'on appelait les francs fiefs dès lors " que l'entrée dudit franc-fief, le feu et le lit [étaient] sur le lieu franc ${ }^{2}$ ». En principe, les pêcheurs qui habitaient ces francs-fiefs auraient donc dû pouvoir décharger leur cargaison sans avoir à payer de coutume mais ce n'était pourtant pas ainsi que les choses se passaient.

En effet, si les pêcheurs avaient dû se rendre à l'hôtel de la Vicomté pour y obtenir les " congés ", autrement dit les autorisations de déchargement, en faisant valoir leurs franchises, ils auraient perdu beaucoup de temps du fait que les navires arrivaient presque tous en même temps et que l'attente aurait été assez longue parce que les clercs étaient plutôt lents à rédiger les documents, ce qui provoquait parfois un décalage de plusieurs jours entre la livraison du poisson et son enregistrement par les responsables locaux. Or, dans le même temps, les marins devaient surveiller le déchargement et le décompte de leurs prises, "le hareng de chaque vaisseau [étant] jeté par milliers et parti en cent ou deux cents parties ", tout en préparant la marée suivante, c'est-à-dire avant tout l'avitaillement du bateau.

C'est pourquoi les pêcheurs avaient été amenés depuis très longtemps à faire appel à des intermédiaires que les textes appellent des hôtes ${ }^{3}$. Cette institution n'était pas propre à la ville de Dieppe et se retrouvait dans de nombreux autres ports, notamment à Boulogne-sur-Mer et à Fécamp ${ }^{4}$. Le terme avait, comme aujourd'hui, un double sens. Il désignait d'abord ceux que le Coutumier de la ville appelle les "hôtes-vendant " ou les " hôtesvendeurs " qui se chargeaient des formalités administratives à la place des pêcheurs qui, dès lors, devenaient eux-mêmes leurs " hôtes ", puisqu'ils étaient en leur " hostage ". Ces bourgeois allaient théoriquement chercher les autorisations de déchargement sans distinguer sur le moment les

1. Une queue contenait en principe 4450 poissons (Arch. dép. de Seine-Maritime, $\left.\mathrm{G} 499, \mathrm{f}^{\circ} 22\right)$.

2. Arch. dép. de Seine-Maritime, G 908.

3. Mollat, Michel, "Les hôtes et les courtiers dans les ports normands à la fin du Moyen Âge ", Revue historique de droit français et étranger, $4^{\mathrm{e}}$ série, t. XXIV, Paris, 1946-47, p. 49-67; repris dans Études d'histoire maritime, Turin, 1977.

4. Ernest DESEILLE y voit une " sorte de corporation entre hôtes bourgeois et hôtes mariniers " (Étude sur les origines de la pêche à Boulogne-sur-mer (932-1550), Boulogne-sur-Mer, impr. de C. Aigre, 1874, p. 19-20). On retrouvait aussi des hôtes à Saint-Valery-en-Caux. Hellot, Amédée, Les Travaux des ports de pêche pendant le Moyen Âge au Pays de Caux, Paris, E. Dumont, 1891, p. 20 et p. 28. MorinièRe, Noël de la, Histoire générale des pêches, Paris, Imprimerie Royale, 1815, pièce $n^{\circ}$ 80. Les hôtes existaient aussi à Bayonne dès le XII ${ }^{\mathrm{e}}$ siècle (BALASQuE, Jules, Études historiques sur la ville de Bayonne, 3 vol., Bayonne, E. Lasserre, 1862-1875, p. 140). 
poissons francs des autres ${ }^{5}$. En réalité, le passage devant la recette de la Vicomté n'était pas toujours réellement fait par l'hôte-vendeur car les plus puissants d'entre eux avaient engagé des clercs qui se déplaçaient à leur place et surtout tenaient leurs comptes ${ }^{6}$. Les hôtes-vendeurs fournissaient aussi aux pêcheurs qui dépendaient d'eux l'" estorement " des navires, c'est-à-dire le ravitaillement en nourriture, en boisson et en matériel de pêche qui leur était nécessaire pour pouvoir repartir aussi vite que possible. Pendant qu'ils étaient à terre, les marins pouvaient également leur demander de leur avancer de la nourriture ou de la boisson, les comptes étant apurés à la fin de la campagne de pêche. En 1429, par exemple, le marin Laurençon Clémence qui était entré dans une maison de prostitution, uniquement pour y prendre un repas, disait-il, avait demandé à son compagnon d'aller avec deux pots vides en l'hôtel de Colin de Greiges, son hôte-vendeur, pour y quérir deux pots de cervoise qu'ils boiraient en mangeant. Cette fourniture n'avait pas posé de problème puisque le marin était revenu presque immédiatement avec la cervoise sans rien payer sur le moment puisque les comptes seraient apurés à la fin de la harengaison ${ }^{7}$.

Les hôtes pouvaient aussi garder les biens de certains particuliers. En 1414, ce même Colin de Greiges avait, par exemple, accepté de placer chez lui un coffre ferré recouvert de cuir contenant cent vingt-neuf écus et des biens estimés à deux mille francs, appartenant à un certain Colard de Calleville dont on ignore s'il participait à la harengaison ${ }^{8}$. Les hôtes-vendeurs se chargeaient enfin d'écouler les poissons pêchés par ceux qu'ils représentaient. Cela concernait avant tout les harengs mais éventuellement tous les autres poissons. En novembre 1426, c'est Jean Loutrel qui avait vendu à l'archevêque un marsouin pris dans les filets d'un de ses hôtes lors de la harengaison et, en mai suivant, Jean Doublet avait, quant à lui, vendu une oie de mer prise par un autre pêcheur ${ }^{9}$.

Certains hôtes-vendeurs, tels Baudouin Eude et Jean Loutrel, étaient propriétaires de bateaux de pêche, parfois en association avec les pêcheurs eux-mêmes et ils recevaient ainsi tout ou partie de la cargaison dont ils faisaient la déclaration devant la Vicomté ${ }^{10}$. Enfin, les hôtes-vendeurs, comme leur nom l'indique, se chargeaient aussi de l'écoulement des poissons livrés par les pêcheurs qui dépendaient d'eux. Ils se comportaient donc un peu comme des mareyeurs achetant et revendant les poissons amenés sur les

5. Certaines années, le paiement des droits d'entrée était reporté à la fin de la campagne. En 1377, le sergent royal qui agissait au nom du chapitre de la cathédrale de Rouen prit en sa main les sommes que huit hôtes conservaient par-devers eux au titre de la harengaison (Arch. dép. de Seine-Maritime, G 3705, cote 49).

6. En 1414-1415, Jeannin Labbé était le clerc d'Étienne Vasselin et il négocia notamment les droits que devrait payer un certain Tassart Houel pour faire sortir du port des harengs et d'autres denrées (Ibid., G 500, f ${ }^{\circ} 8$ ).

7. Arch. nat., JJ $174, \mathrm{n}^{\circ} 281, \mathrm{f}^{\circ} 124 \mathrm{v}^{\circ}$.

8. Arch. nat., X1 1 $/ 60, \mathrm{f}^{\circ} 423,22$ décembre 1414.

9. Arch. dép. de Seine-Maritime, G 502, $\mathrm{f}^{\circ} 53 \mathrm{v}^{\circ}$.

10. Arch. dép. de Seine-Maritime, G 504, f ${ }^{\circ} 5$. 
quais de Dieppe, et il est probable que c'est de cette activité qu'ils tiraient la plus grande part de leurs revenus. C'étaient d'ailleurs les mêmes hommes qui dominaient la harengaison et qui faisaient enregistrer les arrivées de harengs de "saffare " et de maquereaux pêchés assez loin au large ainsi que les importations et exportations de poissons ou d'autres marchandises, par l'intermédiaire de marchands, à destination de la Flandre ou de l'Angleterre ${ }^{11}$.

L'activité des hôtes était donc théoriquement fondée sur la confiance et l'honnêteté. C'est pourquoi ils devaient prêter serment de donner la quantité exacte de harengs déchargés par ceux qu'ils représentaient, ainsi que le prix auquel ils avaient été vendus; ils en devenaient de surcroît les représentants légaux. C'est pour cela qu'en décembre 1408, Naudin Eude se chargea de l'amende qu'aurait dû payer l'un de ses hôtes-pêcheurs qui avait vendu 250 harengs, déjà cédés à une autre personne par son frère Baudouin Eude. Les mêmes poissons ayant été vendus deux fois, c'est Naudin Eude qui paya l'amende et se fit sans doute rembourser par le pêcheur à la fin de la campagne de pêche ${ }^{12}$.

Ces bourgeois manipulaient donc, en théorie, les sommes d'argent destinées à payer les " congés " de débarquement et celles qui auraient dû être versées aux pêcheurs pour la vente de leurs poissons. Ils devaient donc disposer de ressources relativement importantes et de fait, plusieurs d'entre eux appartenaient aux familles bourgeoises les plus riches de la ville. De leur côté, les moins puissants étaient amenés à leur emprunter de l'argent en vendant des rentes. En septembre 1407, à la veille de la harengaison, Jean Bouchart l'aîné, dont le père qui portait le même nom venait de mourir, fut amené, pour être en mesure de continuer à exercer cette activité, à vendre au procureur Jean Le Cauchois une rente de 112 livres qu'il dut gager sur les biens de sa femme Alison ${ }^{13}$.

\section{Les activités des hôtes-vendeurs}

On le voit, les interventions des hôtes-vendeurs dans les activités de pêche étaient variées mais ils agissaient aussi dans les secteurs les plus divers. L'hôte-vendeur Jean Bouchart, qui n'avait qu'un rôle modeste lors

11. Degryse, R., " Het schip en de zeevisserij te Dieppe in de 15de eeuw (Le navire et la pêche maritime à Dieppe au Xve siècle) ", Académie de Marine de Belgique, Anvers, 1975, p. 62 .

12. Arch. dép. de Seine-Maritime, G 499, fol. 33. Toutefois, en décembre de la même année un des marins, hôte de Bérenger Vasselin, qui avait essayé de vendre sept cents harengs à un habitant de Saint-Saëns sans payer de droit d'acquit fut condamné à 26 deniers d'amende qu'il paya lui-même.

13. Arch. dép. de Seine-Maritime, 2E1/162, f ${ }^{\circ} 58,2$ septembre 1407 et 64 v $^{\circ}, 23$ septembre 1407. Comme il avait oublié d'associer sa femme à cette vente, il lui fallut repasser devant le tabellion trois semaines après le premier acte. Il n'est pas certain qu'il y ait eu deux opérations car les deux actes fixent la vente à cent douze livres et demie mais donnent des modes de paiements différents. 
de la harengaison, était aussi qualifié de seigneur de l'Écu parce qu'il tenait l'auberge du même nom ${ }^{14}$. Si Jean Bouchart, comme son père, n'était pas un personnage puissant dans la ville et devait souvent emprunter, il n'en allait pas de même pour les autres hôtes-vendeurs qui appartenaient au monde des notables et qui, grâce à leur puissance financière et à leur importance sociale, participaient à toutes sortes d'opérations économiques ou politiques.

Ce fut le cas pour la famille Vasselin qui joua un rôle essentiel à Dieppe au cours des derniers siècles du Moyen Âge, au moins dans le commerce et la distribution des produits de la pêche. Les Vasselin avaient de ce fait une autorité certaine dans la ville, ce qui leur permettait d'intervenir dans les actes officiels. En 1369, Étienne Vasselin fut le témoin d'un mineur à qui il confirma la possession d'une maison. Son cousin Bérenger Vasselin fit la même chose en 1382 pour une maison de la Grande Rue appartenant aux héritiers d'un certain Richard Bénard. Bérenger Vasselin participait à toutes les activités commerciales de la ville, intervenant comme hôte-vendeur, non seulement dans le commerce du hareng mais aussi dans celui du vin, du sel, du fer et des produits divers rassemblés par les receveurs dans le chapitre des denrées mêlées ${ }^{15}$. C'est d'ailleurs pour y entreposer du fer en attendant de le vendre qu'en 1408, Bérenger Vasselin loua aux hommes de l'archevêque une "seulle " dans sa maison de la Grande Rue ${ }^{16}$. Il plaçait aussi son argent en rentes pesant sur plusieurs maisons de la ville ${ }^{17}$ et percevait ainsi des revenus complémentaires. Le titre de Maître qui lui fut donné à partir de 1408, et jusqu'à sa mort, par les receveurs prouve qu'il jouait aussi un rôle important dans l'administration municipale.

De même, la famille Loutrel, qui dominait le milieu des hôtes-vendeurs, fut incontestablement une des plus puissantes de la ville ${ }^{18}$. Dès 1360 , Guillaume Loutrel avait pris à ferme, avec Martin de Ronchoy, l'imposition sur les cuirs entrant dans la ville. En 1364, son fils Ancel fit partie de la délégation de bourgeois qui ratifia l'autorisation de décharger du blé venant de Flandre accordée aux Rouennais Jacques le Lieur et Ricard Oger, ce qui signifie qu'il devait être conseiller de la ville. En 1376, c'est auprès d'Ancel Loutrel qu'un sergent royal essaya de connaître le montant des revenus de la pêche à Dieppe cette année-là, ce qui montre que la famille dominait déjà l'activité d'hôte-vendeur ${ }^{19}$.

14. Arch. dép. de Seine-Maritime, G 501, $\mathrm{f}^{\circ} 22 \mathrm{v}^{\circ}$ et 24 . Un Jean Bouchart était tavernier à Villejuif en 1446. Peut-être avait-il quitté Dieppe après la prise de la ville par les Français (Comptes du domaine de la ville de Paris, éd. Alexandre Vidier, Léon Le Grand et Paul Dupieux, Paris, Imprimerie Nationale, 1948, t. 1, p. 489).

15. Arch. dép. de Seine-Maritime, G 499, f $17 \mathrm{v}^{\circ}, 23 \mathrm{v}^{\circ}, 25 \mathrm{v}^{\circ}, 28 \mathrm{v}^{\circ}$ et $33 \mathrm{v}^{\circ}$.

16. Bibliothèque nationale de France (BnF), Manuscrits français (fr.) 26022 [1104].

17. Il percevait par exemple quarante sous sur une maison appartenant à Denis Plomme, Arch. dép. de Seine-Maritime, 2E1/172, $\mathrm{f}^{\circ} 125 \mathrm{v}^{\circ}, 21$ avril 1426.

18. Tieullier, Guillaume, Le Coustumier de la Vicomté de Dieppe, éd. E. Coppinger, Dieppe 1884 , p. 58-59.

19. Arch. dép. de Seine-Maritime, G 3705, cote 49. 
À partir du moment où les impôts royaux devinrent réguliers, la famille se tourna vers cette activité qui ne pouvait pas manquer d'être lucrative. En 1382, Bérenger, le cousin d'Ancel, était receveur des aides, en particulier de l'aide nouvellement ordonnée pour le passage de la mer, dans les vicomtés d'Aumale, de Neufchâtel et de Gournay et dans les comtés d'Eu et de Longueville ${ }^{20}$. Cette aide s'appliquait évidemment à Dieppe et Bérenger Loutrel se chargeait d'envoyer à Paris l'argent que réclamaient les receveurs ${ }^{21}$. Il était en contact régulier avec les élus installés à Rouen et se chargeait des transferts d'argent destinés au roi et au duc de Bourgogne ${ }^{22}$. Il s'était installé à Arques et resta en fonction au moins jusqu'en janvier 1393. À la fin du XIV siècle, la famille était également représentée par Richard Loutrel, qui profitait lui aussi des impôts royaux et, en 1395, était associé à David Miffant, Jean Carrel et plusieurs autres hôtes-vendeurs pour la ferme de l'aide de douze deniers par livre perçue sur les transactions de harengs et de poissons de mer $^{23}$. En 1417, en tant que conseiller de la ville, il fit partie du groupe de bourgeois qui participa, en présence de Guy Le Bouteiller, à l'éviction du grenetier armagnac Mahieu Le Cat et à son remplacement par le bourguignon Colin de Neufville ${ }^{24}$.

En 1408, un autre Loutrel, Motin, également hôte-vendeur notamment pour la harengaison, était associé avec des Espagnols pour le commerce des vins. Depuis 1402, son frère Jean, surnommé Finet ou Finot, qui était lui aussi, et comme ses ancêtres, impliqué dans le commerce du hareng et du maquereau, était, à cette date, le plus important des hôtes représentant des pêcheurs ${ }^{25}$. Il plaçait son argent en rentes, parfois devant les tabellions rouennais, et avait également une activité politique dans la ville. Les deux frères, Motin et Jean, quittèrent la ville lorsque les Français s'en emparèrent en 1435 et Jean Loutrel fut parmi les Dieppois dont le roi Henri VI confirma les privilèges. En juillet 1442, ce même roi lui donna un délai de six mois pour faire la prisée de tous les fiefs et de toutes les terres qu'il était supposé posséder dans les bailliages de Rouen, Alençon et Caen, parce qu'ils se trouvaient dans des zones difficiles d'accès à cause de la guerre ${ }^{26}$. À une date inconnue, il devint receveur du roi dans le diocèse de Lisieux où il resta apparemment en poste jusqu'en $1461^{27}$, ce qui explique qu'il apparaît peu dans le tabellionage rouennais.

D'autres Loutrel étaient restés à Dieppe après 1435. C'était le cas en particulier pour Jeannin, le fils de Richard, qui avait participé en 1425 à la production nouvelle de la bière et à sa commercialisation. Il possédait également des bateaux de pêche et en fit notamment réparer un peu avant

20. BnF, fr. 26021 [902].

21. BnF, fr. 26022 [1035].

22. BnF, Nouvelles acquisitions françaises (NAF) 2320 [91, 92, 93 et 94].

23. BnF, fr 26026 [2107]. Ce qui donna lieu à un procès.

24. BnF, fr 26042 [5232].

25. Arch. dép. de Seine-Maritime, G $498, \mathrm{f}^{\circ} 4 \mathrm{v}^{\circ}$ et $\mathrm{G} 499$, $\mathrm{f}^{\circ} 20$.

26. BnF, Pièces originales 1760, dossier 40454, Loutrel [5].

27. BnF, Pièces originales 1760, dossier 40454, Loutrel [4 et 7] et fr. 26073 [5225]. 
la harengaison de $1425^{28}$. En 1429, il se retrouva aux côtés de Robert Eude, de Robert de Carcuit et de son cousin Rogerin pour s'opposer aux représentants de l'archevêque à propos des franchises de la harengaison ${ }^{29}$. Lorsque la ville redevint française, il se rallia au nouveau pouvoir et accepta la charge de "sénéchal de Dieppe pour le roi notre sire " jusqu'à sa mort, en $1438^{30}$. Un autre Loutrel, prénommé Thomas, s'intéressait plutôt aux fermes, notamment à celle de la foire Saint-Jacques qu'il prit en $1426^{31}$. Il exerçait la fonction de mercier et pouvait se fournir en marchandises assez facilement grâce aux activités marchandes du reste de sa famille

L'autre grande famille dieppoise d'hôtes-vendeurs de la période est celle des Eude. Dès 1347, un certain Baudouin était déjà engagé dans les affaires liées à la pêche et au commerce portuaire. Il possédait, en 1364, au moins une saline dans le bourg voisin de Bouteilles car son activité dans le commerce du poisson l'obligeait à disposer de grandes quantités de sel ${ }^{32}$. Il faisait le commerce de nombreux produits, comme le plâtre qu'il faisait venir de Rouen ${ }^{33}$. Comme Ancel Loutrel, il fit partie, avec son fils Roger, de la commission qui, en novembre 1364, autorisa Jacques Le Lieur et Richard Ogier à décharger dans le port du blé venant de Flandre qui commençait à s'échauffer ${ }^{34}$. En 1407, son petit-fils, Vincent, acheta à un Rouennais une autre maison dans la rue de la poissonnerie, c'est-à-dire proche du lieu où il exerçait son activité principale : il était également hôte-vendeur ${ }^{35}$ mais il s'intéressait aussi à la production de cervoise et possédait au moins un moulin à gruau en $1409^{36}$.

À cette date, son cousin, appelé lui aussi Baudouin, exerçait la fonction d'hôte-vendeur comme la plupart des membres de sa famille et il se consacrait également au commerce du poisson et des marchandises passant par le port ${ }^{37}$. En 1395, il faisait notamment le commerce du sel inutilisé pendant la harengaison, qu'il entreposait dans sa maison et pour lequel il devait payer la gabelle ${ }^{38}$. Avec ses compagnons hôtes-vendeurs moins puissants, Jean Bouchart, Raoullin Le Moigne et Vivian Painteur, qui représentaient aussi le marchand de sel Guillaume Le Cauf, il avait pris à ferme l'imposition royale de douze deniers par livre perçue sur les harengs et autres poissons de mer dans la ville de Dieppe. Le fils aîné de Baudouin, prénommé

28. Arch. dép. de Seine-Maritime, G 501, $\mathrm{f}^{\circ} 18 \mathrm{v}^{\circ}$.

29. Arch. dép. de Seine-Maritime, G 504, $\mathrm{f}^{\circ} 35 \mathrm{v}^{\circ}$. Tous les trois firent l'objet de l'enquête menée par Jacques Cochon.

30. Arch. dép. de Seine-Maritime, G 505, $\mathrm{f}^{\circ} 31 \mathrm{v}^{\circ}$. Il touchait 50 livres par an. L'article est rayé et la mention de sa mort est indiquée dans la marge.

31. Arch. dép. de Seine-Maritime, G 502, $\mathrm{f}^{\circ} 18$.

32. Arch. dép. de Seine-Maritime, G 851, $\mathrm{f}^{\circ}$ LXXI et $\mathrm{f}^{\circ}$ LXXVIII.

33. BnF, fr. 26008 [599]. Le plâtre fut ensuite livré à Arques, en décembre 1368.

34. Tieullier, Guillaume, Le Coustumier de la Vicomté de Dieppe..., op. cit., p. 59.

35. Arch. dép. de Seine-Maritime, 2E1/162, $\mathrm{f}^{\circ} 4 \mathrm{v}^{\circ}, 23$ mars 1407. La famille du vendeur, Guillaume Gouel, avait vécu à Dieppe quelques décennies plus tôt.

36. Arch. dép. de Seine-Maritime, G 499, $\mathrm{f}^{\circ} 15 \mathrm{v}^{\circ}$.

37. Arch. dép. de Seine-Maritime, G 3705, cote 49.

38. BnF, fr. 26026 [2078]. 
Regnault, fut d'ailleurs anobli par un acte officiel du roi Charles VI daté du 9 mai 1389, ce qui était pour la famille la reconnaissance officielle de sa puissance locale et nationale. Les raisons de cette décision ne sont pas mentionnées dans l'acte royal qui se contente de constater que Regnault Eude et ses descendants pourraient, à l'avenir, jouir des privilèges découlant de leur nouveau statut tout en en assumant les devoirs, en particulier dans le domaine militaire ${ }^{39}$.

Au moment de la conquête anglaise de la Normandie, le chef de la famille était un autre Baudouin, qui avait hérité de la noblesse de son grand-père Regnault ${ }^{40}$. Il était en relations étroites avec des marchands de poisson parisiens qui étaient ses correspondants en particulier sur le plan financier. Il achetait aussi des produits de valeur dans les régions du nord de l'Europe. En 1425, c'est lui qui vendit, par exemple, les « bors d'Illande " utilisés pour réparer les portes et fenêtres de l'hôtel de la Vicomté. C'est également lui qui livra une pièce de cent trente-huit livres de plomb en masse qui provenait sans doute d'Angleterre ${ }^{41}$. Michel Mollat a attiré, à juste titre, l'attention sur ce personnage qui fut, avec plusieurs autres membres de sa famille, un des plus fervents partisans des Anglais au cours des années où ceux-ci contrôlèrent la ville ${ }^{42}$. Très tôt, il se rallia aux Bourguignons et fut un proche de Guy Le Bouteiller, d'abord capitaine de la ville avant d'exercer la même fonction à Rouen au moment du siège. Son rôle dans la ville et dans la municipalité l'amena à signer la capitulation de la ville, ce qui lui permit de conserver son titre de noblesse et la totalité de ses biens. Il obtint, peu de temps après, l'office de contrôleur du grenier à sel, ce qui lui permettait d'être sûr d'avoir du sel pour les poissons dont il assurait la commercialisation et surtout d'accroître son pouvoir dans la ville puisqu'il était chargé des montres de la garnison. En 1435, la prise de Dieppe par Charles des Marets et les partisans de Charles VII le mit temporairement en difficulté. Il fut d'abord jeté en prison et ne put sortir qu'en payant une rançon que lui avança le roi d'Angleterre. Il se réfugia à Rouen où des lettres royales lui permirent, comme à Jean Loutrel, de conserver ses privilèges et, en particulier, les franchises dont il jouissait à Dieppe ${ }^{43}$. Il obtint aussi des sauf-conduits pour exporter de la laine vers l'Angleterre ${ }^{44}$.

Au moment des trêves de 1444, il était qualifié d'" écuyer, seigneur des terres et héritages qui furent et appartinrent à Jean Bérengault en son vivant prêtre ", c'est-à-dire de terres nobles de la région d'Omonville, voisine de Dieppe, dont il avait obtenu le droit de retarder la prisée de six

39. Arch. nat., JJ 135 [236], f 118.

40. Arch. dép. de Seine-Maritime, 2E1/176, 14 janvier 1433.

41. Arch. dép. de Seine-Maritime, G 501, f 62 et 65.

42. Mollat, Michel, Le Commerce maritime normand à la fin du Moyen Âge, Paris, Plon, 1952, p. 45-46 et surtout p. 479-481.

43. Arch. dép. de Seine-Maritime, 2E1/163, f ${ }^{\circ}$ 153, 5 février 1414.

44. BRÉQUIGNY, Louis Georges de, "Rôles normands et français et autres pièces tirées des archives de Londres par Bréquigny en 1764,1765 et 1766 ", publiées par L. PuISEUX, Mémoires de la société des Antiquaires de Normandie, t. XXIII, 1858, [1340]. 
mois parce qu'elle était située " en pays où nos adversaires fréquentent souventes fois et, à cause de cela, n'avait pas encore pu faire la juste valeur de ses héritages ". Il craignait, en effet, que les gens des comptes à Rouen ne mettent " empêchement au jouissement de ces terres " notamment, s'il y avait " patronage d'église ou garde de sous-âgé ou présentation de bénéfices ${ }^{45}$."

Il conserva ses fiefs nobles après la reconquête de la Normandie par Charles VII et rentra presque aussitôt à Dieppe ${ }^{46}$. Il se qualifiait désormais de marchand et redevint hôte-vendeur dès la harengaison de 1450, année où il se classa au cinquième rang pour le total des acquits qu'il paya à la Vicomté. Ses intérêts avaient donc été préservés et il avait retrouvé une partie de ses hôtes parmi les pêcheurs. Peut-être avait-il été remplacé dans ses activités par Ancelot Miffant dont la part dans la harengaison qui avait augmenté en son absence baissa de manière spectaculaire à son retour. Il intervenait d'ailleurs aussi dans le commerce et, en mars 1451, paya des acquits de chargement de cuirs, de draps et de poissons au nom de quatre marchands non dieppois ${ }^{47}$. En outre, en mai 1451, il servit de témoin lorsque Colin Coulombel, originaire de la paroisse Saint-Sauveur de Rouen, devint bourgeois de Dieppe ${ }^{48}$. Ainsi, non seulement son statut de bourgeois n'avait pas été remis en cause par les autorités archiépiscopales, mais son honorabilité était restée intacte dans la ville, à tel point qu'il était qualifié de conseiller par le receveur qui évoquait sans doute une charge qu'il avait assumée au temps de l'occupation anglaise ${ }^{49}$. En 1457, il était qualifié d'écuyer, ce qui prouve que le roi Charles VII lui avait conservé son titre et n'avait pas sanctionné son soutien actif aux Anglais au cours des décennies précédentes. Ses revenus étaient néanmoins inférieurs à ce qu'ils avaient été et, en juin de la même année, il transforma en une rente de 20 livres, la somme de 130 écus d'or qu'il avait empruntée au vicomte d'Arques pour

45. BnF, Pièces originales 1089, dossier 24956, Eudes, [9]. On peut se demander toutefois dans quelle mesure cette demande n'était pas destinée aussi à échapper au " service féodal " qu'il devait pour ces fiefs (CURRY, Anne, "Le service féodal en Normandie pendant l'occupation anglaise (1417-1450) ", dans La France anglaise au Moyen Âge, Actes du $111^{\mathrm{e}}$ congrès national des Sociétés savantes, (Poitiers, 1986), Paris, Éd. du CTHS, t. 1, p. 249).

46. Preuve que ses intérêts à Dieppe avaient été sauvegardés car il était possible de l'accuser de lèse-majesté et de lui confisquer ses biens. Le roi avait toutefois accordé de nombreuses amnisties aux villes normandes (BossuAT, André, "Le rétablissement de la paix sociale sous le règne de Charles VII ", Le Moyen Âge, t. 70, 1954, p. 160. Ordonnances des rois de France de la troisième race. Quatorzième volume, contenant les ordonnances depuis la vingt-cinquième année du règne de Charles VII, jusqu'à sa mort en 1461, éd. Louis George de Bréquigny Paris, Imprimerie royale, 1790, t. XIV, p. 75-78).

47. Arch. dép. de Seine-Maritime, G 511, f $22 \mathrm{v}^{\circ}$. Sa participation aux acquits de maquereaux resta toutefois limitée.

48. Colin Coulombel avait apparemment quitté définitivement Rouen où il vendit tous ses biens quelques semaines plus tard. Arch. dép. de Seine-Maritime, 2E1/185, 20 juillet 1451.

49. Arch. dép. de Seine-Maritime, G $511, \mathrm{f}^{\circ} 13 \mathrm{v}^{\circ}$. 
rembourser un autre emprunt qu'il avait fait au chapitre cathédral lorsqu'il vivait à Rouen et qu'il n'avait pas pu rembourser à la date prévue ${ }^{50}$.

L'évolution de la famille Miffant fut du même type mais son origine était peut-être différente. Les membres de cette famille avaient incontestablement une puissance financière non négligeable qui leur permettait de faire partie du groupe restreint des hôtes-vendeurs. On ignore presque tout de leurs activités et de leurs relations familiales avant le milieu du $\mathrm{XIV}^{\mathrm{e}}$ siècle, mais il est probable qu'ils participaient déjà au commerce portuaire et à la pêche aux harengs comme les autres notables connus de la ville. Pendant les décennies suivantes, les comptabilités de la seigneurie archiépiscopale montrent que plusieurs membres de cette famille intervinrent effectivement fréquemment dans ces deux secteurs. Ils possédaient des bateaux et participaient aux constructions navales dans la ville. En 1371, Colart Miffant, associé à Bérenger Loutrel, Guillaume Donnevis et Mahieu de Clares, se chargea de faire construire deux barges pour le roi, ce qui devait leur rapporter 2500 florins ${ }^{51}$. Colart Miffant disposait d'ailleurs d'assez d'argent pour faire enterrer sa femme dans l'église Saint-Jacques ${ }^{52}$. En effet la fortune des Miffant était sans doute considérable et avait permis à ses membres de multiplier les achats de biens immobiliers et de rentes mais aussi les avances d'argent. Cette fortune leur permettait également de participer à l'affermage des impôts royaux et, en 1395, David Miffant, associé à d'autres notables comme Richard Loutrel, avait pris la ferme de l'imposition de douze deniers par livre de valeur sur les transactions de harengs et de poissons de mer ${ }^{53}$.

La puissance des Miffant leur permit de s'intégrer aussi à la gestion de la ville. David Miffant, le fils du fermier des aides, possédait en 1408 une maison sur les quais qu'il avait achetée peu de temps auparavant à Henri Maugier ${ }^{54}$. Il faisait le commerce du poisson en association avec d'autres bourgeois de Dieppe et, en 1409, une de ses nefs participa à la guerre de course, attaqua un bateau de pêche anglais et rapporta des harengs, des morues et du saumon ${ }^{55}$. En 1417, David Miffant, le fils du précédent, participa à l'assemblée générale des bourgeois qui décida de destituer le grenetier Mahieu Le Cat et de le remplacer par Colin de Neufville. Il entérina également la reddition de la ville. C'est sans doute parce qu'il disposait de fonds importants immédiatement disponibles qu'il devint le grenetier de Dieppe, alors que Jean Loutrel puis Baudouin Eude n'avaient que la fonction de contrôleur. Il se faisait aider par ses deux fils, Colin et Jean, qui se chargeaient en particulier des transferts vers Rouen et Paris de l'argent

50. Arch. dép. de Seine-Maritime, 2E36/5, f $186 \mathrm{v}^{\circ}, 25$ février 1457, f $242 \mathrm{v}^{\circ}$, SaintBarnabé en juin 1457 et $\mathrm{f}^{\circ} 284 \mathrm{v}^{\circ}, 11$ juin 1457.

51. BnF, Pièces originales 55928, Ribaut [10].

52. Arch. dép. de Seine-Maritime, G 8112.

53. BnF, fr. 26026 [2107].

54. Arch. dép. de Seine-Maritime, G 499, f 38.

55. Arch. dép. de Seine-Maritime, G 499, $\mathrm{f}^{\circ} 30$. 
issu de la gabelle ${ }^{56}$. Par ailleurs, il était également en relations suivies avec des Allemands et, dans une moindre mesure, avec des Flamands et des Hollandais.

Comme d'autres membres de sa famille tels Ancelot ou Guieffroy, David Miffant était l'hôte de plusieurs pêcheurs lors de la harengaison. Sa position de grenetier était donc très intéressante puisqu'elle lui permettait de se procurer du sel en priorité, pour lui ou pour ses amis, lorsque la production de cette denrée commença à se ralentir à Bouteilles à cause de la détérioration de la situation militaire. En juin et juillet 1425, après avoir été déchargé du bateau qui l'avait apporté à Dieppe, une grande quantité de sel fut ainsi distribuée à trois des hôtes de la ville, Guieffrot Miffant, Jean Bouchart et Thomas Mainet, qui la revendirent l'année suivante car ils se faisaient aussi marchands de sel ${ }^{57}$. L'activité de son cousin Ancelot était également multiforme. En plus de son activité d'hôte-vendeur, il était marchand de bois et, en 1425, c'est lui qui vendit le "bois à ardoir " utilisé dans l'hôtel de la Vicomté à l'occasion de la venue de l'archevêque ${ }^{58}$. En 1426, par exemple, Ancelot Miffant vendit une " large et épaisse hune de chêne de vingt pieds de long " pour maintenir le solier de la haute maison de l'hôtel de la Vicomté ${ }^{59}$. Il achetait ce bois à l'occasion des "ventes " qui se faisaient à intervalles réguliers dans les forêts voisines de Dieppe. En 1433, après une violente tempête qui frappa la côte, il mit la première enchère "sur trente-quatre hêtres tant versés et rompus que encore l'un sur l'autre ${ }^{60}$ ». Un de ses enfants, prénommé Colin, continua ensuite cette activité et en 1455, Ancelot Miffant, associé à Guillaume Mainet, acheta du bois dans la Haye d'Arques ${ }^{61}$.

David Miffant quitta sa fonction de grenetier peu avant 1430 et on ne lui connaît pas de successeur, peut-être parce que le grenier ne fonctionnait plus ou avait été réorganisé ${ }^{62}$. Peut-être avait-il senti que la situation militaire était en train de changer et préféré la prudence. Aussi, quand la ville fut occupée par les troupes françaises, les Miffant restèrent sur place, même si leur puissance fut un peu réduite, notamment dans la harengaison, mais la pêche les intéressait toujours et Jeannin Miffant prit à ferme la coutume des poissons en 1448. Cette année-là, Ancel prit également la ferme des moulins à eau, ce qui ne fut pas une bonne opération, mais on comptait trois membres de la famille, David, Ancel et Yolette parmi les brasseurs. Ancel, qui payait le droit de trois étals de boucher, participait aussi à la guerre de course et fit refaire une " roualle " de 18 tonneaux ${ }^{63}$. En 1446, Ancel et Jean Miffant faisaient partie du groupe de notables qui s'étaient

56. BnF, Pièces originales 1962, 45008, Miffant, [3, 4, 5, 8 et 9].

57. Arch. dép. de Seine-Maritime, 100 J 17 [30].

58. Arch. dép. de Seine-Maritime, G 501, f ${ }^{\circ} 76$.

59. Arch. dép. de Seine-Maritime, G 501bis, $\mathrm{f}^{\circ} 32$.

60. BnF, fr. 26057 [2095].

61. BnF, Pièces originales 1962, 45008, Miffant, [2]; 2E36/5, $\mathrm{f}^{\circ} 81 \mathrm{v}^{\circ}, 8$ novembre 1455.

62. BnF, fr. 26054 [1516] et Pièces originales 1962, 45008, Miffant, [10].

63. Arch. dép. de Seine-Maritime, G 509, $\mathrm{f}^{\circ} 38$. 
proclamés "procureurs des autres bourgeois ${ }^{64}$ ". Leurs relations avec les hommes de l'archevêque étaient ambiguës et en 1450, Ancel Miffant obtint d'être dispensé d'une amende de cent sous que lui avait infligée le bailli pour une raison que l'on ignore ${ }^{65}$.

Après la reconquête de la Normandie par Charles VII, la famille retrouva une situation très confortable et des activités officielles. En 1507, Guieffroy Miffant, devenu noble avec le titre d'écuyer, était l'un des "élus pour le roi dans l'élection d'Arques ${ }^{66}$ " et, en 1574, Charles Miffant, seigneur d'Ancourt, du fief de la Motte et du fief-ferme de Gourmecourt, fut anobli contre une lettre de finance de mille livres ${ }^{67}$. Bien que sans doute d'origine juive, cette famille avait donc connu une ascension liée, comme pour les autres familles importantes de la ville, au commerce et à la possession de bateaux mais elle avait su éviter les choix politiques trop tranchés et diversifier très tôt ses activités dans tous les secteurs depuis les impôts jusqu'à la boucherie ou la brasserie.

\section{Les pêcheurs et la guerre de course}

Si les hôtes-vendeurs pouvaient diversifier leurs activités dans la rente, la ferme des impôts et la politique locale ou régionale, les possibilités des pêcheurs étaient plus limitées. Certains possédaient des terres à la campagne ou des jardins sur les places vides qui s'étaient multipliées au lendemain de la peste, mais la majorité d'entre eux - autant que les sources nous permettent de le dire - participaient à la guerre de course, dont les profits pouvaient être plus importants même s'ils étaient plus risqués ${ }^{68}$. Cette activité était une pratique ancienne, dans laquelle les Dieppois avaient souvent un rôle prépondérant. En 1295, pour venger la destruction par les Anglais d'un convoi de deux cents petits bâtiments qui étaient allés chercher du vin en Guyenne, Philippe le Bel autorisa les ports normands à rassembler une flotte dans laquelle il y avait 45 navires dieppois, qui prit et brûla Douvres ${ }^{69}$.

64. BnF, fr. 26075 [5502].

65. Arch. dép. de Seine-Maritime, G 509, $\mathrm{f}^{\circ} 78 \mathrm{v}^{\circ}$.

66. BnF, Pièces originales 1962, 45008, Miffant, [11].

67. GUIBERT, Michel Claude, Mémoires pour servir à l'histoire de la ville de Dieppe, (1761), publiés par Michel Hardy, Dieppe, A. Renau, 1878, p. 399. Il se faisait appeler Minfant.

68. Bochaca, Michel, ArIZAGa Bolumburu, Beatriz, Tranchant, Mathias, "La violence en mer et dans les ports du golfe de Gascogne à la fin du Moyen Âge : Bilans et perspectives de recherche ", dans Augeron, Michel et Tranchant, Mathias (éd.), La Violence et la mer dans l'espace atlantique, Rennes, PUR, 2004, p. 27-50. BERNARD, Jacques, " Les Bordelais dans la guerre navale au $\mathrm{xv}^{\mathrm{e}}$ et au Xvi ${ }^{\mathrm{e}}$ siècle (1406-1550) ", Revue historique de l'Armée, 4, numéro spécial, 1961.

69. JAL, Auguste, Archéologie navale, Paris, A. Bertrand, 1840, t. 1, p. 294 sqq; CHAPELAIS, P., "Règlement des conflits internationaux franco-anglais au XIve siècle (1293-1377) ", Le Moyen Âge, 1951, n 57, p. 271-272; et "Enquête de 1331 sur l'usage des représailles maritimes entre la France et l'Angleterre ", Ibidem, p. 297-298. DARSEL, Joachim, " La protection des flottes du vin au Moyen Âge dans la Manche et dans l'Atlantique ", Bulletin philologique et historique, 1957, [1958]. 
Quand, en 1337, la guerre de Cent Ans commença officiellement, les Dieppois - dont de nombreux pêcheurs - y participèrent immédiatement. Une première attaque française eut lieu le 24 mars 1338 contre Portsmouth et la ville fut prise sans coup férir ${ }^{70}$. Selon certains auteurs locaux, les Français se seraient emparés de Southampton le 5 octobre $1338^{71}$. D'après Froissart, les Français tuèrent " moult de gens et violèrent plusieurs dames et pucelles, dont ce fut grand dommage. " Ils pillèrent la ville qui était " drue et bien garnie " et chargèrent le butin dans leurs navires. Après quoi, ils " cinglèrent à l'exploit du vent devers la Normandie et s'en vinrent rafraîchir à Dieppe où ils se départirent le butin ${ }^{72}$."

Cette activité de guerre se retrouva en 1340 lorsque le roi Philippe VI rassembla une flotte pour aller attaquer les Anglais à l'Écluse. Plusieurs navires vinrent mouiller dans le port de Dieppe ${ }^{73}$, où se trouvait l'amiral, le chevalier de Houdetot, qui y rassemblait les garnisons du bailliage de Caux $^{74}$. Les représentants des Normands, lors de la réunion des États de 1339, n'avaient en effet accepté de voter des subsides permettant de lever une armée de 4000 hommes que si ces contingents étaient utilisés en vue d'un débarquement en Angleterre sous la conduite du duc de Normandie, le futur Jean le Bon ${ }^{75}$. Parmi les navires dieppois, on trouvait en mai 1340, la nef Saint-Pol dont le propriétaire et capitaine, Gautier Le Sueur, participait chaque année à la harengaison et reçut 60 livres pour payer le ravi-

70. RYMER, Thomas, Foedera, conventiones, litterae et cujuscunque generis acta publica inter reges Angliae (1327-1344), éd. Frederic Holbrooke, Londres, G. Eyre and A. Strahan, 182I-1836, t. II/2, pars. IV, p. 12. Lettre d'Édouard III aux châtelains de Wight.

71. Dely, Arthur, Notice historique et géographique sur la ville de Dieppe et ses environs, Dieppe, Louis Vidière, 1930, p. 10. Peut-être s'agissait-il de la prise de Portsmouth par les troupes de Behuchet. L'attaque sur Southampton a été menée par des Monégasques. Arch. dép. de Seine-Maritime, 16 F 2. Rymer, Thomas, Foedora, conventiones..., op. cit., t. II/3, pars. II, p. 164. Selon DAVIES, J.S., A History of Southampton, Southampton, Gilbert \& Co, 1883, p. 60 et p. 465-466, l'attaque aurait eu lieu en octobre 1338 et aurait amené les responsables de la ville à se lancer dans la construction de fortifications. Cette attaque fut l'œuvre de Normands, de Picards, de Génois et d'Espagnols.

72. Il est peu probable que, comme l'écrivent certains érudits locaux, le butin ait servi à la construction des fortifications de la ville (Roche, André, Dieppe et sa région au fil des ans. De l'Antiquité à la fin du deuxième millénaire, Luneray, Bertout, 2000, p. 29), d'une part parce que celles-ci n'étaient pas encore commencées, d'autre part parce que les marins restaient propriétaires de leur part de butin tandis que le financement était collectif. À la rigueur, on pourrait supposer que le roi aurait donné une partie de sa part ou que les écumeurs avaient prêté à la ville de quoi lancer les travaux. Encore faudrait-il des documents pour le confirmer.

73. BnF, NAF 9241, cité par MERLIN-ChAZELAS, Anne, Documents relatifs au clos des Galées de Rouen, Paris, Bibliothèque Nationale, 1977-1978, t. 2, texte XxvII. Robert Bertran sire de Fauguernon était commissaire pour la garde des frontières de la mer des eaux de l'Ouest (des Wes) de Saint-Clément jusqu'au Mont-Saint-Michel avec trois cents hommes d'armes et mille hommes à pied. BnF, NAF 7413, f $^{\circ} 296$.

74. BnF, fr. 25996 [233].

75. Coville, Alfred, Les États de Normandie. Leurs origines et leur développement au $X I V^{e}$ siècle, Paris, Imprimerie Nationale, 1894, p. 49-50. 
taillement de son équipage pendant deux mois ${ }^{76}$. On trouvait aussi la nef Notre-Dame de l'Assomption qui appartenait à Guillaume Caletot et la nef Notre-Dame de la Nativité menée par Gilbert Pollin, tous deux pêcheurs en temps de paix ${ }^{77}$. Un autre Dieppois, Jean de Greiges, possédait, lui, deux navires, le Raseur et la Pèlerine, qu'il confiait à des capitaines tandis que le capitaine d'un bateau de pêche, Mahieu Le Mire, dirigeait la barge SaintGeorges qui appartenait au roi ${ }^{78}$.

Selon les Grandes Chroniques de France, l'amiral Behuchet n'aurait pas voulu engager des gentilshommes et n'aurait retenu que de " pauvres poissonniers et mariniers, pour ce qu'il en avait grand marché; et de tels gens fit-il l'armée. " Quarante et un navires dieppois transportant 1770 hommes dont 120 arbalétriers participèrent à cette bataille ${ }^{79}$ aux côtés des marins de Boulogne-sur-Mer ${ }^{80}$ tandis que six autres barges royales étaient " armées de gens de Dieppe ${ }^{81}$ ". L'expédition fut mal préparée ${ }^{82}$ et cette " grande armée de la mer " fut " déconfite ${ }^{83}$ ". La liste des propriétaires et des maîtres de nef comprenait un certain nombre de capitaines de bateaux de pêche ${ }^{84}$ qui furent remboursés de leurs pertes par un octroi accordé à Dieppe et à Saint-Valéry-sur-Somme ${ }^{85}$. Il est probable que les pertes humaines furent importantes et qu'elles eurent des conséquences sur la prospérité de la ville. Ces pertes furent toutefois apparem-

76. BnF, Clairambault, 104, p. 8133 [177]. La quittance indique un effectif de cent hommes pendant deux mois. Peut-être s'agit-il seulement de cinquante hommes par mois. Le ravitaillement était composé de viande (chair), poissons, chandelle et de tonneaux vides pour mettre de l'eau.

77. BnF, 87, p. 6865 [119] et 24, p. 1731 [55].

78. BnF, 55, p. 4189 [85] et 74, p. 5821 [210].

79. Les Dieppois avaient fourni la deuxième flotte en effectif après celle de L'Eure qui comptait 53 navires et plus de 4000 hommes. Bibliothèque nationale de France Nouvelles acquisitions françaises $9241 \mathrm{f}^{\circ}$ 5-43. Cité par MERLIN-CHAZELAS, Anne, Documents relatifs..., op. cit., t. II, p. 20-64; CANEL, A., Les Normands au combat naval de l'Écluse 24 juin 1340, Rouen, L. Deshays, 1872. Siméon Luce maintient cette hiérarchie mais compte seulement vingt-huit bateaux dieppois dont deux de deux cents hommes et deux appartenant au roi pour quarante-deux bateaux de L'Eure dont trois transportant plus de deux cents hommes. (" Discours sur les préliminaires de la bataille navale de l'Écluse, prononcé en séance publique de la Société des antiquaires de Normandie [jeudi 23 novembre 1882]) ", Bulletin de la Société des antiquaires de Normandie, Caen, imp. Le Blanc-Hardel, 1883, p. 8), chiffre repris par FRÉVILLE DE LORME, Charles Ernest de, Mémoire sur le commerce maritime de Rouen depuis les temps les plus reculés jusqu'à la fin du XVe siècle, Rouen, Le Brument, 1857, t. I, p. 262. Il y avait aussi quelques navires d'Étretat et de Fécamp (FALLUE, Léon, Histoire de la ville et de l'abbaye de Fécamp, Rouen, Nicétas Fériaux, 1841, p. 225).

80. SEWARD, Desmond, The Hundred Years War: the English in France, 1337-1453, Londres, Penguin Putnam Inc, 1996, p. 43.

81. BnF, NAF 9241.

82. Récit de la bataille de l'Écluse dans MordaL, Jacques, Vingt-cinq siècles de guerre sur mer. t. 1 : Aux temps de la rame et de la voile, Paris, Laffont, 1959, p. 47-54.

83. Chronique des quatre premiers Valois (1327-1393), éd. Siméon Luce, Paris, Vve de J. Renouard, 1862, p. 10-12 (LuCE, Siméon, "Les Normands à la bataille de l'Écluse ", Bulletin de la Société des Antiquaires de Normandie, t. XIII, 1883-1885, p. 6).

84. Notamment le Saint-Georges et la Nativité. BnF, Clairambault, 90 et 74.

85. BnF, fr. 25996, p. 235. 
ment prises avec détachement par certains des proches du roi car, selon Froissart, " les Français ne firent pas grand compte de ces Normands et dirent : on n'a rien perdu si ces écumeurs de mer sont morts et péris. Ils n'étaient que larrons [...] et le roi a gagné à leur mort 200000 florins car on leur devait leurs gages de quatre mois ${ }^{86}$. " Même si cette opinion a pu être exprimée, elle ne correspond pas totalement à la réalité car les paiements qui nous sont parvenus montrent que toutes les dettes du roi à l'égard des Dieppois et des autres marins furent effectivement payées. Par contre, cela montre aussi que l'activité de course des pêcheurs dieppois, propriétaires ou non de leurs navires, était considérée comme habituelle et plus ou moins bien acceptée.

Les navires qui participaient à la guerre de course étaient essentiellement des baleiniers, c'est-à-dire des navires très rapides qui, par conséquent, convenaient parfaitement comme le constatait Froissart quand il expliquait que les Normands avaient " en leur armée, vaisseaux que l'on dit baleiniers, que les écumeurs de mer ont par coutume moult volontiers [parce qu'ils] approchent les terre de plus près que les autres vaisseaux ne font ${ }^{87}$ ". Or, les baleiniers étaient aussi et sans doute avant tout des bateaux de pêche - par exemple, en décembre 1408, plusieurs milliers de harengs furent ainsi chargés dans le baleinier de Crespin du Four ${ }^{88}$ - mais ils pouvaient être transformés facilement en navires de guerre.

La peste de 1348 interrompit provisoirement les activités guerrières, mais dans la situation militaire confuse qui suivit, les combats sur la côte et la guerre de course reprirent rapidement. Cette dernière était réglée par un certain nombre de coutumes. Les Français estimaient pouvoir s'en prendre aux Anglais dès lors qu'ils n'avaient pas de sauf-conduits. Selon le Religieux de Saint-Denis, "les corsaires français, $\mathrm{au} \mathrm{Xv}^{\mathrm{e}}$ siècle, sortaient de tous les ports comme des nuées d'insectes ou des bandes de loup pour fondre sur les côtes anglaises ". Quand ils rencontraient un bateau ennemi, l'usage était de crier "Qu'on abatte le tref ", autrement dit la voile, de manière à arrêter la marche du navire afin qu'il puisse montrer ses documents. Si le bateau était " désobéissant ", on pouvait lui courir dessus comme rebelle et ennemi ${ }^{89}$. C'est ce que faisaient régulièrement les marins dieppois. En 1358, certains de leurs bateaux réussirent à s'emparer de plusieurs navires marchands anglais transportant du vin ainsi que d'autres denrées et le

86. Froissart, Jean, Chroniques de J. Froissart, éd. Siméon Luce, Paris, Vve J. Renouard, 1869-1931, Livre $1^{\mathrm{er}}, \S 117$, p. 226. Variante du manuscrit de Rome. Cité sans références par Mollat, Michel, La Vie quotidienne des gens de mer en Atlantique, Paris, Hachette, 1983, p. 183.

87. Froissart, Jean, Chroniques..., op. cit., livre XIII, p. 146.

88. Arch. dép. de Seine-Maritime, G 499, fol. 22 v. Froissart parlait, non sans exagération, de "deux mille chevauls de pourveances " dans les baleiniers anglais (Chroniques..., op. cit., t. XI, p. 326).

89. FRÉVILLE DE LORME, Charles Ernest de, Mémoire sur le commerce maritime..., op. cit., t. II, p. 281. 
régent, le futur Charles $\mathrm{V}$, réclama au nom du roi, la part de l'amiral dont la charge était alors vacante ${ }^{90}$.

Cette activité était donc dangereuse et pouvait être néfaste à la ville car les Anglais, eux aussi, attaquaient les bateaux dieppois comme ceux des autres ports, en particulier au moment de la harengaison, ce qui touchait un secteur vital de l'activité portuaire. Pour mettre un terme à ces pratiques ou, au moins, pour montrer leurs capacités de représailles, les marins du Tréport mirent un baleinier en mer dès 1406 pour attaquer les bateaux anglais ${ }^{91}$. De leur côté, les Dieppois envoyèrent, sous la direction d'un certain Herman, trois barges de guerre, occupées par plusieurs pêcheurs, qui firent, en septembre 1407, une démonstration de force le long des côtes du Suffolk, du Norfolk et du Yorkshire. Les marins s'emparèrent d'au moins quatre navires anglais ${ }^{92}$ et ils firent prisonniers les hommes d'équipage, qu'ils fussent militaires, marchands ou pêcheurs, et ne les libérèrent que contre rançon. Avec plusieurs navires partis d'autres ports de la région, ils attaquèrent également les Flamands considérés comme alliés des Anglais. Au total, cela rapporta aux écumeurs 210 " nobles " d'Angleterre, 4 marcs d'or et plus de 164 livres tournois. Les cargaisons ou les équipements des pêcheurs furent également saisis et revendus ${ }^{93}$. L'année suivante, les trois navires dieppois s'emparèrent d'un navire de Rye et amenèrent leurs prisonniers à Dieppe, mais plusieurs autres, gardés à bord des navires qui mouillaient au Tréport, réussirent à s'enfuir dans des circonstances assez confuses $^{94}$. Malgré le traité de sûreté générale signée entre Saint-Valéry-surSomme et Winchelsea en juin 1408 et publié un peu partout dans la région, notamment à Dieppe ${ }^{95}$, la guerre de course continua, parfois à l'encontre des Flamands et particulièrement des Brugeois ${ }^{96}$.

Les comptes de la seigneurie de Dieppe enregistraient cette activité car les marchandises entrant dans le port devaient payer le " congé " à

90. BnF, fr. 26002 [899]. Il envoya de Neufchâtel à Dieppe, Monseigneur Baudrain de la Heuze, alors " lieuxtenant de son marechal es bailliages de Rouen et de Caux ". Baudrain de la Heuze avait été " maréchal établi " pour la Normandie en 1355 (ConTAmine, Philippe, Guerre, État et société à la fin du Moyen Âge. Études sur les armées des rois de France, 1337-1494, Paris-La Haye, Mouton, 1972, p. 92).

91. FRÉVILLE DE LORME, Charles Ernest de, Mémoire sur le commerce maritime..., op. cit., t. II, p. 281-282.

92. Huguet, Adrien, "Aspects de la guerre de Cent Ans en Picardie maritime ", Mémoires de la Société des Antiquaires de Picardie, 1941, p. 71-73. Les navires s'appelaient La Catherine, L'Aronde et Le Renard. Outre Herman, sans doute un nom de guerre, les deux autres capitaines étaient Tristan Dessure et Guillaume de Wachers dont on ne sait pas s'ils étaient vraiment dieppois (BOUREL DE LA RONCIÈRE, Charles, Histoire de la marine française, Paris, $2^{\mathrm{e}}$ éd, Plon-Nourrit, 1909-1923, t. II, p. 156-158).

93. Huguet, Adrien, "Aspects de la guerre de Cent Ans... ", op. cit., p. 71-73.

94. Ibidem, p. 98.

95. Le texte fut publié par le bailli de Dieppe, Jean Godin, le 15 avril 1409. Archives du Nord, B 552, n 15 149, cité par HugueT, Adrien, Ibidem, p. 113, note 1.

96. Le bourgmestre se plaint de plusieurs attaques contre des navires flamands par certains Normands (bi eenighen van Normandien) (GILLIODTS VAN SEVEREN, Louis, Inventaire des archives de Bruges, Bruges, impr. de E. Gailliard, 1901-1902, t. 4, p. 37). 
l'archevêque comme n'importe quelle autre. En avril 1409, ce furent ainsi onze tonneaux et neuf pipes de vin qui furent déchargés "d'un crayer pris en la mer par écumerie ${ }^{97} "$. Toutefois, les prises d'armement en étaient exemptes. L'" esqueute " prise par Crespien du Four en août de la même année contenait quatre douzaines de "clefs à arbalètes " et quatre "vuidas " également pour les arbalètes qui ne furent pas taxées, alors que le reste de la cargaison l'était ${ }^{98}$. Au cours de la période couverte par le compte, le receveur enregistra au moins cinq de ces bateaux attaqués le plus souvent au cours de l'été, surtout en juillet et août. En juillet 1409, par exemple, David Miffant prit les congés de déchargement pour les produits de la pêche d'un navire " pris en la mer en écumerie " et en août suivant, Crespien du Four déchargea à deux reprises des marchandises diverses provenant d'au moins quatre baleiniers eux aussi "pris en écumerie ${ }^{99}$ ".

La conquête de la Normandie par les Anglais mit provisoirement fin à la guerre de course mais certains marins eurent du mal à arrêter. En 1420, peu de temps avant la reddition, alors que la ville se préparait à reconnaître l'autorité anglaise, un équipage de marins dieppois s'empara d'un baleinier appartenant au duc de Clarence ${ }^{100}$. Dès que la domination du roi d'Angleterre fut reconnue, les Dieppois durent payer une amende pour cette prise. Non seulement les marchandises qui avaient été réparties entre les marins et les armateurs devaient être restituées mais les rançons qui avaient été obtenues des prisonniers devaient être remboursées. Au lendemain de cette affaire, cette activité cessa et les comptes ne mentionnent plus de déchargement de marchandises prises "à la course ", preuve que cette activité ne pouvait se maintenir qu'avec la tolérance des autorités.

C'est pourquoi, dès la prise de Dieppe par les Français en 1435, la guerre de course recommença. Ainsi une branche de la famille Eude, hostile à Baudouin et à ses fils, restée à Dieppe, s'adonna avec ardeur à cette activité. Un certain Rogerin, cousin de Baudouin Eude, qui avait été hôte-vendeur dès 1425, participa à la guerre de course contre les Anglais et, en mai 1438, un de ses bateaux attaqua un navire anglais et rapporta un butin composé de blé, de draps, de peaux et de résine ${ }^{101}$, preuve que les pêcheurs n'étaient parfois que les acteurs de cette activité prédatrice, sans en être vraiment les commanditaires. De même, en 1437-1438, plusieurs hôtes-vendeurs,

97. Arch. dép. de Seine-Maritime, G 499, fo 26.

98. Arch. dép. de Seine-Maritime, $\mathrm{f}^{\circ} 30 \mathrm{v}^{\circ}$.

99. Arch. dép. de Seine-Maritime, $\mathrm{f}^{\circ} 30 \mathrm{v}^{\circ}$.

100. BREQUIGNY, Louis Georges de, «Rôles normands et français et autres pièces tirées des archives de Londres par Brecquigny en 1764, 1765 et 1766 ", Mémoires de la société des antiquaires de Normandie, $3^{\mathrm{e}}$ série, Caen, $1858, \mathrm{n}^{\circ} 319$. Il n'est pas sûr que ce navire ait fait partie de la flotte royale anglaise qui comptait trente navires à cette date (RicHMOND, C. F., "English Naval Power in the Fifteenth Century ", History. février 1967, vol. 52, n 174, p. 1-15).

101. Arch. dép. de Seine-Maritime, G 505, f 24 et $24 \mathrm{v}^{\circ}$. 
notamment Ancel Miffant et Jean Le Moigne, se firent construire un bateau neuf destiné à la guerre de course ${ }^{102}$.

Lors des négociations qui aboutirent à la paix d'Arras qui mettait fin à la guerre entre le royaume de France et le duché de Bourgogne, il fut décidé que la guerre de course à l'encontre des Flamands cesserait et se concentrerait désormais sur les navires anglais. Les Anglais devinrent effectivement les principales cibles des écumeurs dieppois. En août 1439, on informa Lord Scales, qui se trouvait alors à Caen, du fait que « des vaisseaux étaient partis de la ville de Dieppe pour aller en la mer et porter nuisance aux sujets du roi "; un mois plus tard, Henry Standich qui commandait un bateau " mis sur la mer pour la garde de la dite mer à l'entrée de la gueule de Seine " fut averti que des navires s'étaient rassemblés à Dieppe avec l'intention de lui nuire autant qu'ils le pourraient ${ }^{103}$.

Pourtant, avec le soutien du capitaine de la ville Charles des Maretz, les Dieppois continuèrent à attaquer leurs navires jusque dans le port de l'Écluse ${ }^{104}$, estimant ainsi s'en prendre aux Hollandais et à des Hanséates qui commerçaient toujours avec les Anglais ${ }^{105}$. La situation perdura donc et, en 1441, des corsaires dieppois - pêcheurs pendant la saison - s'emparèrent d'une nef de Dordrecht sous le prétexte qu'elle portait des marchandises appartenant à des Anglais alors qu'elle était en réalité chargée de biens appartenant à des Allemands de Cologne et destinés à l'Angleterre ${ }^{106}$. Le capitaine de la ville de Dieppe, Charles des Marets, justifiait la poursuite de ces activités auprès du dauphin en expliquant que les Flamands avaient toujours des relations avec les Anglais et que, de ce fait, ils pouvaient toujours être considérés comme des ennemis du royaume ${ }^{107}$. La première mention connue d'une prise des Dieppois sur les Flamands date du 2 mai 1441, ce qui provoqua l'envoi d'une lettre du duc de Bourgogne à Charles des Marets "touchant le bien du West-pays de Flandres ". En 1443, selon des représentants de la ville de Bruges, l'équipage d'une « scaffe " qui faisait ce type de guerre comprenait en effet des marins originaires " aucuns de Flandres, aucuns de Zélande, autres d'Allemagne, autres de Boulogne sur mer et illec environ, et autres de Dieppe " sous la direction d'un certain Jean Taguelare, natif de Nieuport en Flandre. Ils attaquaient les bateaux pêcheurs flamands pour leur voler de la cervoise et épiaient les navires

102. Arch. dép. de Seine-Maritime, $\mathrm{f}^{\circ} 6 \mathrm{v}^{\circ}$ et 7 .

103. BnF, fr. 26066 [3844 et 3855].

104. Escouchy, Mathieu d', Chronique, Paris, éd. G. du Fresne de Beaucourt, 1863-1864, t. III, pièces justificatives, p. 99; BOUDIER, Anne, La guerre de course au XV siècle. Marins et corsaires au temps de Charles des Marets, Rouen, 1926, passim, p. 9.

105. SNeller, Z.W. et Unger, W.S., Bronnen tot de Geschiedenis van den Handel met Frankrijk. Erste Deel, La Haye, 1930, n 174.

106. ThielEMAns, Marie-Rose, Bourgogne et Angleterre : relations politiques et économiques entre les Pays-Bas bourguignons et l'Angleterre (1435-1467), Bruxelles, Presses universitaires de Bruxelles, 1966, p. 339.

107. Il est de fait que les Flamands n'approuvaient pas totalement la politique de leur duc et craignaient les représailles des Anglais, notamment dans le domaine économique (Ibidem, p. 71-72). 
marchands qui représentaient leurs prises les plus intéressantes ${ }^{108}$. Un autre écumeur, Pierre Féré, qui possédait plusieurs navires de pêche, commandait les barges dieppoises sous les ordres de Charles des Marets mais il travaillait surtout pour son propre compte ${ }^{109}$. Il écumait en particulier la Manche et la mer du Nord, à la tête d'escadres "de diverses nations ". En 1441 , après avoir fait escale dans le port de l'Écluse ${ }^{110}$, il lança son baleinier, L'Éveillé qui dort, contre plusieurs navires anglais et en prit un qu'il voulut ramener à Dieppe. Au cours du voyage, les bateaux dieppois furent attaqués par des Flamands qui récupérèrent le bateau de Pierre Féré et firent prisonniers plusieurs marins qui furent exécutés à Bruges, ce qui créa un fort climat d'hostilité entre les Dieppois et les Flamands au cours des années suivantes ${ }^{111}$, et cela d'autant plus que, dans le même temps, des bateaux d'Eu avaient également été capturés dans le port de Nieuport ${ }^{112}$.

Les trêves de Tours en 1444 confirmèrent que les Dieppois devaient cesser d'attaquer les navires flamands. Pourtant, une lettre d'un allemand datée de février ou mars 1445 signale la prise d'un navire de l'Écluse et en avril, un bourgeois de Dieppe, c'est-à-dire en fait un marin-pêcheur, Robin Parey, attaqua une escute chargée de cervoise appartenant à un marchand de Dunkerque; mais le bateau s'échoua sur le rivage et la cervoise fut perdue, ce qui représentait, d'après ses propriétaires, plus de cent quarantedeux nobles d'or. Le même Robin Parey attaqua ensuite un autre navire appartenant à un bourgeois de Malines qu'il rançonna tout en lui prenant sa cargaison, puis une nef de Brabant à qui il fit subir le même sort ${ }^{113}$. Il fallut une intervention directe du roi Charles VII pour que la guerre de course à l'encontre des navires flamands cessât réellement.

Une fois la Normandie reconquise, la guerre de course devint un moyen d'empêcher les Anglais de ravitailler leurs troupes restées sur le continent. Le compte de 1450 enregistre ainsi les cargaisons d'une vingtaine de navires " pris à la guerre ", essentiellement des navires de commerce ${ }^{114}$. En mars 1450, le fils de Guillaume Harenc, qui avait repris l'activité de patron de pêche de son père, attaqua avec son baleinier un navire anglais chargé de vin et de toiles. Associé à Michel et Jacques Le Zwolle, il s'empara

108. Boudier, Anne, "Charles Desmarets, corsaire dieppois. Documents inédits ", Revue Historique, t. CXXXVII, 1921, P.J. II, p. 8-9.

109. Il s'était installé dans une maison de la rue du Pilori, à proximité du port (Arch. dép. de Seine-Maritime, G $511, \mathrm{f}^{\circ} 53 \mathrm{v}^{\circ}$ ).

110. Le port de Bruges était alors un " lieu de sûreté " où tous les navires de quelque nation qu'ils fussent, même ennemies, pouvaient faire escale, "sans faire guerre ou prise l'une sur l'autre ", BOUdIER, Anne, "Charles Desmarets... ", op. cit., p. 8-9.

111. Ibidem, P.J. I, p. 7.

112. DecK, Suzanne, La Ville d'Eu, son histoire, ses institutions, 1151-1475, Une commune normande au Moyen Âge, Paris : E. Champion, 1924, p. 60.

113. Zweite Abteilung : Hancereces sevon 1431-1476, éd. G. Von des Ropp, t. I-VII, Leipzig, 1876-1892. t. III, n² 208, p. 113.

114. Arch. dép. de Seine-Maritime, G 509, $\mathrm{f}^{\circ} 56 \mathrm{v}^{\circ}$ à 66 . Le nombre exact de navires reste incertain car le receveur indique parfois l'arrivée de "plusieurs navires pris à la guerre ", car ce qui l'intéresse, ce sont les cargaisons sur lesquelles il peut prendre des acquits. 
aussi d'une nef appartenant à l'armateur anglais Sentheen ${ }^{115}$. La guerre de course avait, en effet, pris une ampleur nouvelle que le compte de cette année-là permet de mesurer partiellement car toutes les prises n'étaient pas mentionnées du fait qu'un certain nombre de marins étaient bourgeois de Dieppe et ne payaient donc aucune taxe sur les marchandises qu'ils rapportaient dans le port. Les écumeurs pouvaient, en effet, être maîtres de leur navire mais parfois ils dirigeaient seulement des navires affrétés par des Dieppois dont les noms ne sont pas toujours indiqués. En février 1450, Jean Le Roy, dit Dauphin, menait une barge appartenant à Jean Le Moigne, hôte-vendeur lors de la harengaison, tandis que Jean Notin qui dirigeait sa propre nef était originaire de Belleville-sur-Mer un port situé à proximité de Dieppe. Seuls, les étrangers à la ville voyaient donc leurs prises enregistrées par le receveur de l'archevêque et il est possible que les trois nouveaux bourgeois d'octobre 1451, natifs de Rouen, du pays de Bray et du Boulonnais, eussent été en fait des marins ou des capitaines de nef installés à Dieppe et participant à la course. Tous trois eurent, en effet, comme témoins Guillaume Harenc et Jean Monnaulx, très impliqués dans cette activité et, grâce à leur nouveau statut, ces marins allaient maintenant pouvoir échapper aux taxes de déchargement de leur butin ${ }^{116}$.

En 1450, dix-huit maîtres de nef agissant généralement à plusieurs participèrent à ces opérations, certains revenant dans le port plusieurs fois à quelques semaines d'intervalle. En janvier, il fallut trois bateaux pour prendre un navire de commerce anglais, qui fut ensuite amené dans le port et déchargé d'une cargaison assez hétéroclite, comprenant aussi bien des " bors d'Illande " que de l'huile d'olive et de " rabette ", de la cire, de l'étain et des draps ${ }^{117}$. Les navires qui menaient ces opérations étaient de types divers mais leur taille était apparemment supérieure à celle des navires réparés ou construits dans le port au cours des années précédentes. Jean Bense et Jean Falaize qui agissaient ensemble en mars 1451 possédaient, comme la plupart des autres écumeurs, des baleiniers dont certains étaient qualifiés de petits, ce qui signifie que les autres étaient de plus grand tonnage; on trouvait aussi des "roualles" et des " escarvelles ${ }^{118}$ ".

Les navires attaqués étaient sans doute majoritairement anglais mais le compte ne le précise pas toujours. Un navire au moins venait de Bretagne mais il s'agissait peut-être aussi d'un navire anglais qui était allé s'y ravitailler. En 1450, on n'attaqua apparemment que des bateaux de commerce, moins à même de se défendre, comme la barge à hune prise par un groupe de trois baleiniers en avril. Toutefois, en juillet, c'est une barge à château qui fut déchargée de sa cargaison de draps et de morues ${ }^{119}$.

115. Arch. dép. de Seine-Maritime, G 509, f $\mathrm{f}^{\circ} 52$.

116. Arch. dép. de Seine-Maritime, G 511, $\mathrm{f}^{\circ} 11 \mathrm{v}^{\circ}$.

117. Arch. dép. de Seine-Maritime, G 509, f $^{\circ} 58$. Robin Achier et Guillaume Harenc étaient maîtres de leurs bateaux et dieppois. Le troisième Jean Desmarquets devait être étranger à la ville.

118. Ce terme ne désigne pas une caravelle, mais est tiré du terme néerlandais " karveel ». 119. Arch. dép. de Seine-Maritime, G 509, $\mathrm{f}^{\circ} 56 \mathrm{v}^{\circ}$ à 66. 
L'année suivante, les écumeurs s'en prirent aussi aux bateaux qui transportaient des poissons préparés. En février, plusieurs baleiniers affrétés par Ancelot Miffant, Crespien du Four et Jean Le Roy, dit Dauphin, amenèrent à Dieppe six navires pris à la guerre qui contenaient plusieurs milliers de harengs caques et de harengs saurs ainsi que des morues et du saumon ${ }^{120}$ et le fait se reproduisit quatre fois cette même année. Les autres opérations de course permirent d'apporter des marchandises diverses, comprenant beaucoup de draps, d'autres étoffes comme de la futaine, du vin, de la bière et du cuir. Par contre, une " nef à prisonniers " venant d'Angleterre ne fut enregistrée que pour une haquenée ${ }^{121}$.

Tous ces écumeurs faisaient de Dieppe leur port de repli et y amenaient leurs prises, c'est-à-dire le plus souvent le bateau lui-même qui était parfois revendu. Un document des années 1445-1450 rapporte un conflit qui opposa un marchand d'Abbeville à l'écumeur dieppois Guillaume Harenc. Ce dernier lui avait vendu la moitié du bateau qu'il possédait avec Michel Le Jolle parce que ce marchand en avait besoin pour effectuer un transport de blé. Or, tandis qu'il faisait escale à Calais, le bateau avait été arrêté "à la requête d'un Anglais demeurant dans la ville de Rye en Angleterre disant icelui bateau lui appartenir et qui illicitement lui avait été pris et à lui ôté sur la mer ». C'est pourquoi le marchand demandait à être dédommagé non pas de la perte du bateau mais de celle de ses marchandises qui avaient été gâtées avant d'avoir pu être déchargées ${ }^{122}$.

Les équipages, eux aussi, étaient faits prisonniers et libérés contre rançon - en principe, un maître marin valait douze écus et un matelot six écus - mais les choses ne se passaient pas toujours bien, surtout pour les écumeurs. En novembre 1450, un navire dieppois pris dans une tempête échoua à Katvyn et ses marins furent immédiatement arrêtés avant d'être jugés par la cour de Hollande qui les condamna à mort et les fit exécuter, ce qui provoqua la colère de Charles des Marets ${ }^{123}$.

Les sources concernant le port de Dieppe sont donc assez claires. La pêche, et avant tout, la pêche au hareng en novembre, était l'activité la plus lucrative de la ville. Toutefois, son organisation sociale ne permettait pas à tous les acteurs d'en tirer autant de profit. Une fois de plus, les producteurs réels, c'est-à-dire les pêcheurs, n'en profitaient que peu, surtout quand ils n'étaient pas propriétaires de leurs navires. Les notables de la ville, parce qu'ils étaient hôtes-vendeurs, armateurs et commerçants, en étaient les principaux bénéficiaires avec l'archevêque de Rouen, seigneur de la ville. Les notables y gagnaient une autorité en ville qui leur permettait d'accaparer les fonctions municipales quand celles-ci se mirent en place à l'occasion de la construction des fortifications. Ils prirent aussi à ferme

120. Arch. dép. de Seine-Maritime, G 511, fo 22.

121. Arch. dép. de Seine-Maritime, G 511, f 30 à 34 .

122. Arch. dép. de Seine-Maritime, G 506, $\mathrm{f}^{\circ}$ verso de la page de couverture.

123. BoudiER, Anne, La Guerre de course au Xve siècle..., op. cit. 
les nouveaux impôts royaux et profitèrent des troubles politiques pour occuper des fonctions officielles au nom du roi. Cette diversité d'activité leur permit souvent d'acquérir la noblesse et de sortir de la pêche et du commerce après quelques générations.

Les pêcheurs, eux, n'avaient pas toutes ces possibilités. La guerre de course était donc pour eux, malgré ses risques, un complément de ressources, qui leur permettait de gagner plus en tuant plus, car la guerre de course était dangereuse et ceux qui échouaient le payaient souvent de leur vie. Pourtant, cette activité prédatrice dura encore plusieurs siècles et c'est pour y mettre fin qu'une flotte anglo-hollandaise bombarda la ville à plusieurs reprises en 1694, provoquant un incendie qui réduisit en cendres l'essentiel des archives municipales. C'est à cause de ce désastre, sans doute mérité selon nos normes actuelles, que l'on ne peut pas en savoir plus sur l'ensemble des activités de la ville.

\section{RÉSUMÉ}

La pêche aux harengs était une activité de base pour l'économie de Dieppe Elle ne durait que cinq à six semaines par an au Moyen Âge. Pendant le reste de l'année, les marins comme les marchands de ce poisson devaient rechercher ailleurs de quoi subvenir à leur existence. Parmi les professionnels concernés par cette question se trouvaient les hôtes. Ces derniers s'occupaient, pour le compte des pêcheurs, des formalités administratives nécessaires au déchargement de leurs prises. Au fil du temps, leur position d'intermédiaires les avaient conduits à étendre considérablement le spectre de leurs activités. Ils pouvaient participer à toutes sortes d'opérations économiques ou politiques. Certains étaient aussi marchands de poisson, de vin, de sel et de fer, d'autres encore aubergistes, armateurs, merciers, sauniers, etc. Souvent, ils avaient placé leur capital dans des rentes et jouaient un rôle important dans l'administration fiscale et municipale. Quant aux pêcheurs, leurs possibilités étaient plus étroites. Aussi, profitant du climat d'insécurité que faisait régner la guerre de Cent Ans, beaucoup firent de la guerre de course un complément de ressources appréciable.

\section{ABSTRACT}

Herring fishing was a core activity for the economy of Dieppe. It only lasted five to six weeks a year in the Middle Ages. For the rest of the year, seafarers and fish merchants had to look elsewhere to provide for their needs. Among the professionals involved in this matter were the hôtes. They looked after the administrative formalities necessary for the offloading of the fishermen's catch. Over time, their position as intermediaries had led them significantly to expand the scope of their activities. They could participate in all kinds of economic and political operations. Some traded in fish, wine, salt and iron, whilst others were innkeepers, ship owners, haberdashers or salt sellers. They often invested their capital in annuities and played an important role in fiscal and municipal administration. As for fishermen, their opportunities were more limited. Taking advantage of the climate of insecurity caused by the Hundred Years War, many turned to privateering as significant source of additional income. 